\title{
Requisição de prontuário ou ficha clínica no Brasil (Justiça, Ministério Público e Polícia) x Sigilo Médico
}

Request for medical records or medical records in Brazil (Justice, Public Prosecution and Police) x Medical Confidentiality

Solicitar registros médicos o registros médicos en Brasil (Justicia, fiscales y policías) x secreto médico

Roberta Fernandes Remédio Marques ${ }^{1}$

RESUMO: A requisição de prontuários médicos para a instrução de inquéritos policiais, procedimentos administrativos e processos judiciais é uma realidade no Brasil e desperta inúmeras dúvidas. Este artigo visa, à luz da legislação e da jurisprudência brasileira, trazer alguns esclarecimentos sobre o tema, sem a pretensão de exauri-lo.

Palavras-chave: Segredo médico. Intimidade do paciente. Prontuário médico,

ABSTRACT: The request medical records for the instruction of criminal investigations, administrative and judicial proceedings is a reality in Brazil and arouses many questions. This article aims, in the light of the legislation and case law, bring some clarification on the subject, with no claim to exhaust it.

Keywords: Medical confidentiality. Patient privacy. Medical records.

RESUMEN: La solicitud de registros médicos para la instrucción de las investigaciones policiales, los procedimientos administrativos y judiciales es una realidad en Brasil y suscita muchas preguntas. Este artículo tiene como objetivo, a la luz de la legislación y la jurisprudencia brasileña, trae algunas aclaraciones sobre el tema, sin pretensión de agotarlo.

Palabras-Ilave: Segredo Médico. Intimidad del paciente. Registro médico.

\section{Introdução}

É habitual no Brasil a requisição de prontuário(s) médico(s) pela Justiça (federal, trabalhista, estadual), pelo Ministério Público (federal e estadual) e por Delegacias de Polícia (federal e estadual) aos dirigentes de clínicas e hospitais, que ficam reticentes quanto a melhor conduta a ser adotada, uma vez que a deontologia médica prevê o dever de manter o sigilo médico e nas requisições, constantemente, existe uma ordem (sob as

\footnotetext{
${ }^{1}$ Advogada e professora do ISCAC. Especialista em Direito Processual Civil pela Universidade Federal de Pernambuco - UFPE, Especialista em Direito da Farmácia e do Medicamento pela Universidade de Coimbra - FDUC, Mestre em Ciências Jurídicas pela Universidade de Lisboa - FDUL e Doutora em Ciências Jurídicas Privatísticas pela Universidade do Minho - UMinho.Email: rfernandes@iscac.pt
} 
penas da lei, inclusive, de prisão) para que seja remetido o prontuário à autoridade que o requisite.

Assim, o dirigente vê-se "entre a cruz e a espada": se atender à determinação do Poder Judiciário, do Ministério Público e da Polícia, poderá violar o sigilo médico e infringir as normas de conduta ética; e se não atender, poderá vir a ser "preso". Neste diapasão, mister se faz esclarecer os direitos e deveres em causa, para, ao final, trazer ponderações da conduta a ser seguida. Além destas hipóteses de requisição judicial, analisar-se-á, também, as situações de solicitação de fotocópia do prontuário pelo paciente, por parente do paciente, de menor de idade e por terceiro interessado.

Relativamente à requisição de prontuário médico, mister se faz uma breve explanação sobre o direito à intimidade do paciente, enquanto direito especial de personalidade, o dever de sigilo do médico e as suas exceções.

Com o presente estudo, pretende-se clarificar as dúvidas relativas às solicitações de fotocópias de prontuários, com o intuito de trazer mais clareza ao assunto, que tanto desperta dúvidas quando do recebimento das requisições.

\section{O direito à intimidade do paciente enquanto direito especial de personalidade}

A Constituição brasileira dispõe em seu art. $5 .^{\circ}$, inciso $X$, que "são invioláveis a intimidade, a vida privada, a honra e a imagem das pessoas, assegurado o direito à indenização pelo dano material ou moral decorrente de sua violação". Já o Código Civil Brasileiro estabelece em seu art. 21 a proteção da vida privada, ao prever que a "vida privada da pessoa natural é inviolável, e o juiz, a requerimento do interessado, adotará as providências necessárias para impedir ou fazer cessar ato contrário a esta normal".

Sem adentrar no mérito das discussões doutrinárias a respeito do conceito de vida privada $^{2}$ e, na falta de uma definição legal (1), (2), podemos afirmar que é o direito que

\footnotetext{
${ }^{2}$ Isto porque, embora a normatização faça menção à vida privada e intimidade como se fossem institutos distintos, e a doutrina, por vezes, os diferenciar, na prática, levando em conta unicamente a sua relevância jurídica, não representam maiores diferenças, uma vez que o grau de infração aos aspectos individuais violados será valorado pelo subjetivismo do titular do suposto direito lesado e do órgão que irá julgar a lesão àquele direito personalíssimo.
} 
toda pessoa tem a que permaneçam desconhecidos determinados aspetos da sua vida, assim como a controlar o conhecimento que terceiros tenham dela ${ }^{3}$.

Sendo assim, no âmbito desta análise, utilizaremos a expressão direito à intimidade em sentido lato para designar todos os meios que o sistema constitucional (e cível) disponibiliza para a defesa e proteção judicial dos direitos fundamentais relacionados ao que hoje se denomina autodeterminação informativa dos dados relativos à intimidade da vida privada, e que, por segredo, estas mesmas informações quando repassadas ao confidente geram o dever de confidencialidade, independentemente da origem ser legal ou de mera confiança entre as partes.

Relativamente ao segredo profissional médico, especificamente no tocante a saúde do paciente, entendemos que faz parte da zona mais íntima de cada pessoa e, por isso mesmo, havendo a sua violação, haverá indubitavelmente uma agressão à intimidade do paciente, mesmo que a tomada de conhecimento seja claramente lícita.

\section{O sigilo médico}

O sigilo profissional é o segredo profissional como sendo "a reserva que todo indivíduo deve guardar dos factos conhecidos no desempenho das suas funções ou como consequência do seu exercício, factos que lhe incumbe ocultar, quer porque o segredo lhe é pedido, quer porque ele é inerente à própria natureza do serviço ou à sua profissão" (3). Em algumas situações, a essência de determinadas profissões e a prevalência de impunidade para tais indiscrições, abalaria a reserva da intimidade das pessoas que a elas se submetessem, bem como o próprio interesse público, pois é de máxima valia para a sociedade que as pessoas e o próprio Estado tenham ao seu dispor profissionais responsáveis que velem pelas informações acessíveis em decorrência do ofício.

Constata-se, portanto, que o dever de guardar sigilo, de manter reserva e de não divulgar dados confidenciais abrange todas as modalidades de segredo profissional, pois nessas situações, de maneira geral, três bens jurídicos sempre se fazem presentes: primeiro, a ética profissional; segundo, o livre exercício da profissão que, sem a garantia de uma tutela específica de confidencialidade, restaria prejudicado e em alguns casos

\footnotetext{
${ }^{3}$ Este direito se analisa em dois direitos menores: a) - o direito a impedir o acesso de estranhos a informações sobre a vida privada e familiar; b) - o direito a que ninguém divulgue as informações que tenha sobre a vida privada e familiar de outrem.
} 
inviabilizado; terceiro, o direito à autodeterminação informativa e à intimidade das pessoas que utilizassem tais serviços profissionais (4).

A fundamentação do resguardo do segredo médico tem razão de ser no respeito à intimidade do paciente, preservando, deste modo, um direito natural de personalidade, recepcionado pela Constituição e Código Civil Brasileiro.

Faz-se ainda necessário acrescentar que o sigilo médico deve ser entendido lato sensu, uma vez que abrange toda a equipe de profissionais que compartilhem e tenham acesso às informações relativas ao paciente.

A circulação de informação deverá obedecer a um princípio de confidência necessária em que serão determinantes para definir o âmbito do segredo, o interesse do doente, a natureza da informação e os reflexos que a sua divulgação traz para a sua privacidade.

\section{Regulação jurídica do sigilo médico}

O sigilo médico, enquanto dever indissociável ao direito à intimidade do paciente, é regulado através de diversas esferas jurídicas, cujos dispositivos dispõem de mecanismos para punir a injustificada divulgação das informações confidenciais reveladas ao médico.

São considerados como informação confidencial os fatos revelados diretamente pelo doente, por outrem a seu pedido ou terceiro com quem tenha contatado durante a prestação de cuidados; os fatos de que o médico se apercebeu, provenientes ou não da observação clínica do doente ou de terceiros; bem como os fatos comunicados por outro médico obrigado quanto aos mesmos a segredo profissional. (5)

No plano ético, o Código de Ética Médica do Brasil (Resolução CFM n. $\left.{ }^{\circ} 1.931 / 2009\right)^{4}$ estabelece no art. 73, do capítulo IX, que é vedado ao médico "revelar fato de que tenha conhecimento em virtude do exercício de sua profissão, salvo por motivo justo, dever legal ou consentimento, por escrito, do paciente. Parágrafo único. Permanece essa proibição: a) mesmo que o fato seja de conhecimento público ou o paciente tenha falecido; b) quando de seu depoimento como testemunha. Nessa hipótese, o médico comparecerá perante a autoridade e declarará seu impedimento; c) na investigação de suspeita de crime, o médico estará impedido de revelar segredo que possa expor o paciente a processo penal".

\footnotetext{
${ }^{4}$ No Brasil, o Código de Ética Médica foi definido pelo Egrégio Supremo Tribunal Federal como norma jurídica de caráter especial, submetida a regime jurídico semelhante ao das normas e aos normativos federais, sendo possível o controle da sua constitucionalidade através de ação direta (RTJ 93/506).
} 
A matéria também foi destacada quando da edição da Resolução CFM $\mathrm{n}$. 으 $^{-}$ 1.605/2000, que dispõe sobre a necessidade de preservação do sigilo médico, mesmo diante de requisição judicial: "Art. $1^{\circ}$ - O médico não pode, sem consentimento do paciente, revelar o conteúdo do prontuário ou ficha médica. Art. 3ํㅡ - Na investigação da hipótese de cometimento de crime o médico está impedido de revelar segredo que possa expor o paciente a processo criminal. Art. 4ํㅡ - Se na instrução de processo criminal for requisitada, por autoridade judiciária competente, a apresentação do conteúdo do prontuário ou da ficha médica, o médico disponibilizará os documentos ao perito nomeado pelo juiz, para que neles seja realizada perícia restrita aos fatos em questionamento. Art. 5ำ - Se houver autorização expressa do paciente, tanto na solicitação como em documento diverso, o médico poderá encaminhar a ficha ou prontuário médico diretamente à autoridade requisitante".

Já o Código Processual Civil Brasileiro estabelece em seu art. 363, inciso IV, que à parte e o terceiro podem se escusar de exibir, em juízo, o documento ou a coisa, "se a exibição acarretar a divulgação de fatos, a cujo respeito, por estado ou profissão, devam guardar segredo".

No tocante à legislação criminal, o Código Penal Brasileiro dispõe no art. 154 que é crime revelar, sem justa causa, segredo, de que tem ciência em razão de função, ministério, ofício ou profissão, e cuja revelação possa produzir dano a outrem.

Estes são os principais dispositivos relativos ao segredo médico, embora existam outras, como na esfera administrativa, que o contemple de forma a zelar pelo seu resguardo.

\section{O prontuário médico}

O prontuário médico é o documento onde é armazenada toda a informação de utilidade médica relativa ao estado de saúde, enfermidade e cuidados prestados ao paciente, tornando-se um meio de comunicação muito valioso para a transmissão e posterior utilização das informações constantes no plano de assistência ao enfermo, sendo esta a sua finalidade precípua, cuja obrigatoriedade de elaboração é regulada pelo art. 87 do Código de Ética Médica Brasileiro.

A ficha clínica ou prontuário pertence ao paciente, cuja responsabilidade e guarda é conferida ao médico e/ou hospital, conforme se denota da leitura do art. 88 do Código 
Deontológico Brasileiro, tendo este "acesso a seu prontuário", podendo solicitar fotocópia do mesmo ${ }^{5}$

\section{Exceções ao dever de sigilo médico e acesso aos bancos de dados automatizados e manuais (prontuários médicos)}

Na relação médico-paciente, o segredo absoluto sistemático foi substituído pelo segredo médico relativo, onde a sociedade é levada a excecionar este dever profissional do médico naqueles casos em que haja um conflito entre o interesse privado e o geral, devendo sempre ser levado em conta este último na busca do bem comum.

Uma vez estabelecido o caráter relativo do segredo médico, surge a dificuldade de determinar em que condição se pode considerar excetuada esta obrigação, pois o problema não reside no reconhecimento de uma obrigação genérica de confidencialidade, mas em determinar quais as circunstâncias que justificam a rutura deste dever.

No entanto, a exoneração do dever de segredo somente ocorre nas hipóteses de autorização expressa do interessado ou, excecionalmente, em situações de conflito de bens jurídicos concorrentes que são solucionadas por meio da ponderação legal ou judicial do conflito.

\section{O consentimento informado}

O Código Civil Brasileiro, em seu art. 11 estabelece que "com exceção dos casos previstos em lei, os direitos de personalidade são intransmissíveis e irrenunciáveis, não podendo o seu exercício sofrer limitação voluntária".

Como direito especial de personalidade, e dadas as suas características, o direito à intimidade é disponível, admitindo válidas limitações voluntárias, porque na tutela da

\footnotetext{
${ }^{5}$ Neste sentido a jurisprudência do Superior Tribunal de Justiça: "Processual civil. Recurso especial. Hospital. Acesso a documentos médicos requerido pelo próprio paciente. Negativa injustificada pela via administrativa. Ensejo de propositura de ação de exibição de documentos. Ônus de sucumbência. Princípio da causalidade. - De acordo com o Código de Ética Médica, os médicos e hospitais estão obrigados a exibir documentos médicos relativos ao próprio paciente que requeira a exibição. - A negativa injustificada à exibição de documentos médicos pela via administrativa, que obrigou o paciente à propositura de ação à sua exibição pela via judicial, tem o condão de responsabilizar o hospital pelo pagamento dos ônus de sucumbência, em atenção ao princípio da causalidade, nos termos dos precedentes firmados no STJ. Recurso especial conhecido e provido". (STJ, REsp 540048 / RS, Recurso Especial 2003/0061038-6, Min. Ministra Nancy Andrighi, Terceira Turma, DJ 12/04/2004 p. 207 RDDP vol. 15 p. 125)
} 
intimidade não estamos perante um daqueles interesses gerais cuja forma e graus de satisfação estejam rigidamente pré-estabelecidos.

É verdade que a lesão de qualquer direito sem o consentimento do titular provoca a ilicitude do ato lesivo. Contudo, o consentimento, quando validamente prestado, faz com que a violação passe a ser lícita, dado que limita a invocação do direito em causa.

Para ser válido, o consentimento além de legal, deve ser consciente, isto é, resultante de uma vontade esclarecida, devidamente ponderada e concreta, tendo efetivamente em vista situações determinadas; além disso, por via de regra, deverá será prestado de maneira expressa e não pode ser deduzido de um comportamento anteriormente observado (o consentimento tácito só poderá ser aceito em casos excecionais) (6).

Por outro lado, impõe-se que se preste especial atenção à verificação da integridade do consentimento, uma vez que, sobretudo em situações de necessidade, dependência ou simplesmente inferioridade de poder econômico do titular do direito, as pessoas podem ser levadas a limitar a reserva sobre sua vida íntima por temerem as consequências de uma eventual recusa, como se observa nos contratos de adesão, bastante comuns quando da contratação de um seguro saúde, por exemplo.

A declaração limitativa voluntária também pode, obviamente, ser anulada ou objeto de uma declaração de nulidade, quer com fundamento nas regras sobre incapacidade ou falta ou vício de vontade (art. 138 e ss. do Código Civil Brasileiro).

No tocante à relação médico/paciente, quanto se tratar de paciente plenamente capaz, que possa exprimir a sua vontade, só a este poderão ser fornecidos os dados constantes do prontuário médico ou a pessoa devidamente autorizada ${ }^{6}$

Quando se tratar de incapazes, estes terão de ser representados de acordo com as regras gerais para suprimento de incapacidade estipuladas no Código Civil, embora o mesmo não possa valer nos mesmos moldes para a limitação voluntária de direitos de personalidade de menores.

\footnotetext{
${ }^{6}$ A jurisprudência do Superior Tribunal de Justiça tem admitido a exibição judicial desde que atendido o princípio da proporcionalidade, conforme se observa da ementa ora transcrita: "Administrativa. Mandado de segurança. "Quebra de sigilo profissional". Exibição judicial de "ficha clinica" A pedido da própria paciente Possibilidade, uma vez que o "art. 102 do Código de Ética Médica", em sua parte final, ressalva a autorização. O sigilo e mais para proteger o paciente do que o próprio médico. Recurso ordinário não conhecido". (STJ, ROMS 5821 / SP, Min. Adhemar Maciel, julgamento: 15/08/1996, Órgão Julgador: T6 Sexta Turma, DJ data-07/10/1996, p. 37687).
} 
Isto porque, tendo em vista tratar-se de direitos que tutelam bens pessoais, deverá exigir-se também o consentimento do menor para a sua limitação ${ }^{7}$, se ele já tiver maturidade suficiente.

No entanto, quando o incapaz não tenha maturidade para avaliar as consequências do consentimento, este não será exigível. Nestes casos, os limites dentro dos quais a restrição aos direitos de personalidade é válida deverão ser mais rígidos, para evitar a exploração, pelos representantes legais, das informações sobre a vida privada do incapaz.

Relativamente à questão da saúde e divulgação de seus dados, tais considerações teóricas a respeito da capacidade dos menores e incapazes, revestem-se de essencial importância, uma vez que, em sendo os dados relacionados à saúde direitos personalíssimos que fazem parte da esfera mais reservada do ser humano, a divulgação dos dados constantes dos prontuários médicos e bancos de dados em se tratando de menores deve ser ainda mais restrita.

O Código de Ética Médica dispõe em seu art. 74 que é vedado ao médico "revelar sigilo profissional relacionado a paciente menor de idade, inclusive a seus pais ou representantes legais, desde que o menor tenha capacidade de discernimento, salvo quando a não revelação possa acarretar dano ao paciente". 8

7 Entende que “(...) os incapazes terão de ser representados de acordo com os princípios gerais do suprimento de incapacidades de exercício. Contudo, e uma vez que se trata de direitos que tutelam bens pessoais, deverá exigir-se também o consentimento do menor para a sua limitação, se ele já tiver maturidade suficiente. O mesmo autor complementa dizendo que (...) se deve distinguir consoante o incapaz - menor ou interdito - disponha ou não, no momento em que presta o consentimento, do discernimento necessário (de capacidade natural) para avaliar o sentido e alcance das consequências para o seu direito de personalidade, em resultado da limitação voluntária".

${ }^{8}$ A este respeito, o Supremo Tribunal Federal Brasileiro se pronunciou da seguinte forma: "Constitucional. Processual civil. Legitimidade ativa do Ministério Público para ajuizar ação de investigação de paternidade. Filiação. Direito indisponível. Inexistência de Defensoria Pública no Estado de São Paulo. 1. A Constituição Federal adota a família como base da sociedade a ela conferindo proteção do Estado. Assegurar à criança o direito à dignidade, ao respeito e à convivência familiar pressupõe reconhecer seu legítimo direito de saber a verdade sobre sua paternidade, decorrência lógica do direito à filiação (CF, artigos 226, §§ 3o, 40, 5o e 70; 227, § 60). 2. A Carta Federal outorgou ao Ministério Público a incumbência de promover a defesa dos interesses individuais indisponíveis, podendo, para tanto, exercer outras atribuições prescritas em lei, desde que compatível com sua finalidade institucional (CF, artigos 127 e 129). 3. O direito ao nome insere-se no conceito de dignidade da pessoa humana e traduz a sua identidade, a origem de sua ancestralidade, o reconhecimento da família, razão pela qual o estado de filiação é direito indisponível, em função do bem comum maior a proteger, derivado da própria força impositiva dos preceitos de ordem pública que regulam a matéria (Estatuto da Criança e do Adolescente, artigo 27). 4. A Lei 8560/92 expressamente assegurou ao Parquet, desde que provocado pelo interessado e diante de evidências positivas, a possibilidade de intentar a ação de investigação de paternidade, legitimação essa decorrente da proteção constitucional conferida à família e à criança, bem como da indisponibilidade legalmente atribuída ao reconhecimento do estado de filiação. Dele decorrem direitos da personalidade e de caráter patrimonial que determinam e justificam a 
Com relação ao paciente falecido, e considerando que a personalidade do indivíduo cessa com a morte $(4)^{9}$, poder-se-ia indagar se, nessa ocasião, a informação sobre a sua saúde poderia vir a ser divulgada, ficando à margem de proteção legal, uma vez que, a princípio, nada mais haveria a proteger ao nível de personalidade.

O art. 12 do Código Civil Brasileiro, em seu parágrafo único estipula a proteção da personalidade estende-se mesmo para além da morte das pessoas, ao dispor que "em se tratando de morto, terá legitimação para requerer a medida prevista neste artigo o cônjuge sobrevivente, ou qualquer parente em linha reta, ou colateral até o quarto grau".

Isto porque, a tutela de determinados bens essenciais de uma pessoa pode interessar a outras pessoas que em relação àquela estejam em particular posição. Especificamente sobre a saúde do titular do direito personalíssimo, temos que, de forma geral, é um valor do qual também compartilham os seus filhos e parece assim razoável que, falecido aquele, estes tenham legitimidade para defender um bem que também é deles.

A legitimidade que a certas pessoas é reconhecida pela lei substantiva, não respeita à tutela de bens enquanto objeto dos direitos de personalidade do titular já falecido e sim, à tutela desses bens enquanto eles interessam a tais pessoas que assim agem não como

necessária atuação do Ministério Público para assegurar a sua efetividade, sempre em defesa da criança, na hipótese de não reconhecimento voluntário da paternidade ou recusa do suposto pai. 5 . O direito à intimidade não pode consagrar a irresponsabilidade paterna, de forma a inviabilizar a imposição ao pai biológico dos deveres resultantes de uma conduta volitiva e passível de gerar vínculos familiares. Essa garantia encontra limite no direito da criança e do Estado em ver reconhecida, se for o caso, a paternidade. 6. O princípio da necessária intervenção do advogado não é absoluto (CF, artigo 133), dado que a Carta Federal faculta a possibilidade excepcional da lei outorgar o jus postulandi a outras pessoas. Ademais, a substituição processual extraordinária do Ministério Público é legítima (CF, artigo 129; CPC, artigo 81; Lei 8560/92, artigo $20, \S 40)$ e socialmente relevante na defesa dos economicamente pobres, especialmente pela precariedade da assistência jurídica prestada pelas defensorias públicas. 7. Caráter personalíssimo do direito assegurado pela iniciativa da mãe em procurar o Ministério Público visando a propositura da ação. Legitimação excepcional que depende de provocação por quem de direito, como ocorreu no caso concreto. Recurso extraordinário conhecido e provido". (STF, RE 248869 / SP - São Paulo, Min. Maurício Corrêa, julgamento:136 07/08/2003, Órgão Julgador: Segunda Turma, DJ data-12-03-2004, p. 00038.)

${ }^{9}$ No caso de pacientes falecidos, os familiares e herdeiros poderão ter acesso ao histórico clínico, salvo em caso do falecido haver expressamente proibido a sua divulgação. Em qualquer caso, nunca se facilitará informações acerca da intimidade do falecido e daqueles dados que prejudiquem terceiros. Hoje em dia, um bom número de autores entende que a solicitação de informações constantes dos ficheiros clínicos do falecido deve ser acompanhada de autorização judicial prévia. Por mais legitimado que possa parecer o terceiro, seja o cônjuge, seja o filho ou outro familiar direto, unicamente se fará a entrega do prontuário com a devida autorização judicial. Excetuado, obviamente, aqueles casos em que o falecido, por disposição testamentária, haja consentido o acesso aos seus dados clínicos. 


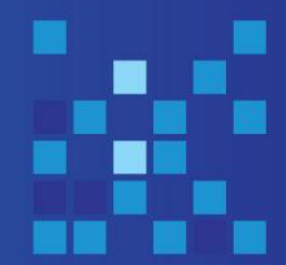

sucessores daquele titular, nem por substituição processual, mas em nome próprio e por direito próprio.

Considerando que essas informações pertencem à intimidade do paciente falecido, a divulgação das mesmas atentaria contra a intimidade do de cujus, cabendo aos familiares a titularidade para defesa dos interesses acaso configure a sua violação.

É de salientar que, como estas informações ficarão à mercê da apreciação valorativa dos entes do falecido, se porventura houver divergência ente a vontade do de cujus declarada através de documento escrito, e a dos familiares, o desejo do primeiro deverá ser respeitado ${ }^{10}(8)$.

Se não houver uma limitação ou restrição por parte do de cujus no tocante à divulgação destas informações, à família é quem caberá definir a sua valoração.

\section{Requisições do poder judiciário, do ministério público e da polícia}

As requisições de ficheiros clínicos ou prontuários médicos pelos órgãos judiciários são bastante frequentes e tratadas de forma diversa, pois despertam dúvidas quanto à obrigatoriedade ou não do seu envio.

Isto porque o diretor clínico do hospital e/ou o médico ficam diante de um impasse: por um lado existe o código deontológico e leis substantivas que reprimem o envio de dados sigilosos e, do outro, as leis que regulam o funcionamento dos diversos poderes judiciários.

É certo que ao Poder Judiciário em sentido amplo compete à administração da justiça, assegurando a defesa dos direitos e interesses legalmente protegidos dos cidadãos, dirimindo os conflitos de interesses públicos e privados.

No entanto, a busca da verdade não poderá colidir frontalmente com os direitos individuais e personalíssimos dos cidadãos, igualmente protegidos pela Carta Magna.

Sendo assim, no que diz respeito às informações repassadas às autoridades judiciais, a lei impõe o dever de o médico comunicar às autoridades competentes os crimes de ação

\footnotetext{
${ }^{10}$ Ao discorrer sobre a divergência entre a vontade da família e do falecido na utilização do cadáver, SILVA se posicionou pela prevalência da vontade deste último: "Problema mais delicado e duvidoso é o de saber se esse direito da família poderá prevalecer contra a vontade do falecido. (...) É preferível, pois, dar-se precedência ao direito de disposição do defunto sobre o direito da família, o que, aliás, é conforme a natureza destas situações jurídicas, como resulta, nomeadamente, da circunstância de, a respeito dos direitos inerentes à piedade familiar, também se fazer prevalecer o direito do cônjuge sobre o dos parentes, e, entre estes, o dos mais próximos sobre o dos mais remotos".
} 
pública que independem de representação, e a constatação de moléstias infectocontagiosas. Isto porque a informação dessas moléstias deve ser feita incondicionalmente porque a lei não traz nenhuma exceção, pois esta norma visa à saúde pública, valor de extrema relevância segundo a ordem jurídica.

O mesmo não acontece com o dever de comunicar crimes. Essa comunicação deve restringir-se aos crimes de ação pública incondicionada - isto é, àqueles que independem de provocação do ofendido e não pode sujeitar o paciente a procedimento criminal ${ }^{11}$.

No tocante à requisição de fichas e boletins médicos por autoridades judiciárias ou policiais, entende-se que o segredo médico, enquanto instituto jurídico, acolhe no seu bojo os referidos documentos que, assim, se submeter ao regime geral e ético próprio que resguarda e tutela o sigilo profissional. $^{12}$

\footnotetext{
${ }^{11}$ É o que estabelece o art. 66, II, da Lei das Contravenções Penais Brasileira, ao reprimir a omissão de comunicação de crime.

${ }^{12}$ A jurisprudência do Supremo Tribunal Federal e do Superior Tribunal de Justiça brasileiro assim já decidiram sobre requisições judiciais: "Segredo profissional. A obrigatoriedade do sigilo profissional do médico não tem caráter absoluto. A matéria, pela sua delicadeza, reclama diversidade de tratamento diante das particularidades de cada caso. A revelação do segredo médico em caso de investigação de possível abortamento criminoso faz-se necessária em termos, com ressalvas do interesse do cliente. Na espécie o hospital pôs a ficha clinica a disposição de perito medico, que "não estará preso ao segredo profissional, devendo, entretanto, guardar sigilo pericial" (art-87 do código de ética medica). Por que se exigir a requisição da ficha clínica? Nas circunstâncias do caso o nosocômio, de modo cauteloso, procurou resguardar o segredo profissional. Outrossim, a concessão do "writ", anulando o ato da autoridade 139coatora, não impede o prosseguimento regular da apuração da responsabilidade criminal de quem se achar em culpa. Recurso extraordinário conhecido, em face da divergência jurisprudencial, e provido. Decisão tomada por maioria de votos". (STF, RE 91218/ SP - São Paulo, Min. Djaci Falcão, julgamento: 10/11/1981, Órgão Julgador: Segunda Turma, DJ data-16-04-82, p. 13407). "Administrativo e criminal. Requisição de prontuário. Atendimento a cota ministerial. Investigação de "queda acidental". ARTS. 11, 102 e 105 do Código de Ética. Quebra de sigilo profissional. Não verificação. O sigilo profissional não é absoluto, contém exceções, conforme depreende-se da leitura dos respectivos dispositivos do Código de Ética. A hipótese dos autos abrange as exceções, considerando que a requisição do prontuário médico foi feita pelo juízo, em atendimento à cota ministerial, visando apurar possível prática de crime contra a vida. Precedentes análogos". (STJ, ROMS 11453 / SP, Min. José Arnaldo da Fonseca, julgamento: 17/06/2003, Órgão Julgador: T5 - Quinta Turma, DJ data-25/08/2003, p. 00324). "Agravo de instrumento - Mandado de segurança contra ato de promotor de justiça - Competência do juízo de primeiro grau - Requisição de prontuário médico pelo Ministério Público em procedimento investigatório - Recusa do profissional Concessão de liminar para assegurar o sigilo médico - Admissibilidade - Decisão mantida - Agravo desprovido - O poder de requisitar documentos conferido ao Ministério Público encontra obstáculo no segredo profissional, como é o caso do sigilo médico, instituído pelo Código de Ética Médica, com respaldo constitucional". (TJPR - Ag Instr 0118624-7 - (20644) - Ponta Grossa - 4르 C.Cív. - Rel. Juiz Conv. Miguel Kfouri Neto - DJPR 01.07.2002). "Habeas Corpus - Determinação judicial para fornecimento de prontuário médico - Constrangimento ilegal - Inocorrência - Alegação de violação ao sigilo previsto no Código de Ética Médica - Inadmissibilidade: - Inteligência: art. 102 do Código de Ética Médica, art. 108 do Código de Ética Médica . Inocorre constrangimento ilegal, sanável via Habeas Corpus, na determinação judicial para Diretor de Hospital fornecer prontuário médico a ser juntado em inquérito que apura possível crime de lesão corporal praticado contra paciente da instituição, vez que o sigilo, previsto no Código de Ética Médica, resguarda a intimidade do doente e não a conduta profissional do Médico, sendo certo ainda que, se a própria vítima
} 
$\mathrm{Na}$ verdade, não há nenhum dever legal que obrigue o médico ou o dirigente de hospital ou clínica a entregar as papeletas, as folhas de observação clínica e os boletins médicos. Não havendo disposição legal respaldando a ordem da autoridade judiciária ou policial, ocorre constrangimento ilegal, porque ninguém será obrigado a fazer ou deixar de fazer alguma coisa senão em virtude de lei ${ }^{13}$.

As informações requisitadas pelos magistrados, a princípio, somente poderão ser atendidas quando não violarem o segredo médico ${ }^{14}$ (dados de internação, etc). Caso contrário, o médico, o funcionário ou o dirigente hospitalar acusará o recebimento do pedido, mas declinará de fornecer qualquer dado, alegando impedimento legal e ético.

No entanto, caso reste imprescindível à informação constante do prontuário para a realização do direito - cuja avaliação da necessidade deverá ser realizada caso a caso -, entendemos que a solução será a nomeação de um perito médico para a análise, in loco, das anotações lançadas no prontuário do paciente, nos termos da Resolução CFM n. ${ }^{\circ}$ 1.605 , de 15 de setembro de 2000 , cujos artigos foram transcritos acima.

\section{Conclusões}

Conclui-se, assim, que os prontuários só poderão ser entregues obedecidas as cautelas acima previstas, que resumidamente enumeramos a seguir:

recorre à Polícia para se queixar de mau atendimento, não existe intimidade a ser assegurada". (HC $281.108 / 0$ data

${ }^{13}$ Esse entendimento foi acolhido pelo Supremo Tribunal Federal Brasileiro ao julgar o Habeas corpus n. ${ }^{\circ}$ 39.308, originário de São Paulo, e cuja emenda é a seguinte: "Segredo profissional. Constitui constrangimento ilegal a exigência da revelação do sigilo e participação de anotações constantes das clinicas e hospitais. habeas corpus concedido."

14 É neste sentido que decidiu o Superior Tribunal de Justiça Brasileiro: "Processo civil - Embargos de declaração - Sigilo profissional - Omissões inexistentes. 1. Explicitado ficou no voto condutor que a entidade hospitalar não está obrigada a enviar à Justiça prontuários médicos. 2. O Tribunal disse, com clareza, que à vista do prontuário, preservados os dados sigilosos quanto à doença e ao tratamento realizado, todos os demais dados relativos à internação não estão ao abrigo do sigilo profissional. 3. Embargos de declaração rejeitados". (STJ, EDROMS 14134 / CE, Min. Eliana Calmon, julgamento: 22/10/2002, Órgão Julgador: T2 Segunda Turma, DJ data-25/11/2002, p. 00214). "Administrativo - Sigilo profissional. 1. É dever do profissional preservar a intimidade do seu cliente, silenciando quanto a informações que the chegaram por força da profissão. 2. O sigilo profissional sofre exceções, como as previstas para o profissional médico, no Código de Ética médica (art. 102). 3. Hipótese dos autos em que o pedido da Justiça não enseja quebra de sigilo profissional, porque pedido o prontuário para saber da internação de um paciente e do período. 4. Recurso ordinário improvido". (STJ, ROMS 14134 / CE, Min. Eliana Calmon, julgamento: 14/04/1998, Órgão Julgador: T4 - Quarta Turma, DJ data-16/09/2002, p. 00160). 
1) Paciente plenamente capaz, que possa exprimir a sua vontade - só a este poderão ser fornecidos os dados constantes dos ficheiros clínicos ou a pessoa devidamente autorizada.

2) Pacientes incapazes - só poderão ser fornecidos os dados às pessoas que exerçam o poder familiar, tutores e/ou curadores, desde que comprovem esta condição através de prova documental.

3) Pacientes falecidos - por analogia, deverá ser aplicada a regra constante do parágrafo único, art. 12 do Código Civil Brasileiro, e unicamente passadas informações ao cônjuge sobrevivente, ou qualquer parente em linha reta, ou colateral até o quarto grau.

4) Autoridades judiciárias ou policiais - a princípio, somente poderão ser atendidas quando não violarem o segredo médico (data de internação, etc). Caso contrário, o médico, o funcionário ou o dirigente hospitalar acusará o recebimento do pedido, mas declinará de fornecer qualquer dado, alegando impedimento legal e ético. No entanto, caso reste imprescindível à informação constante do ficheiro para a realização do direito, deverá ser aplicada a regra constante da Resolução CFM n. ${ }^{0} 1.605$.

\section{Referências}

1.Pinheiro, J. Privacidade, Segredo Profissional e Saúde nas Instituições, in Revista Portuguesa de Bioética. Coimbra: Edição do Centro de Estudos de Bioética, Maio 2009. p. 65 e ss; e

2.Pereira, A D, Confidencialidade da Informação de Saúde no Direito Português, in Lex Medicinae - Revista Portuguesa de Direito da Saúde, Centro de Direito Biomédico, 8 (16): 54,2011

3 Neves, C, Violação do Sigilo Médico e Exercício llegal da Medicina. Lisboa: Livraria Petrony, 1963. p. 15.

4 Carazo, S, La Intimidad y el Secreto Médico. Madrid: Ediciones Díaz de Santos, S.A., 2000. p. 73.

5 Caldas, C, O Segredo Médico e os Direitos Humanos, in Boletim da Ordem dos Advogados, 4/93, III série, Out/Nov./Dez. p. 5.

6. León, C G, La Proteccion del Paciente y el Consentimiento Informado, in Lex Medicinae - Revista Portuguesa de Direito da Saúde, Centro de Direito Biomédico, 6(12): 15, 2009. 
7 Pinto, P M, A Limitação Voluntária do Direito à Reserva sobre a Intimidade da Vida Privada, in Estudos em Memória do Professor Doutor Paulo Cunha. Lisboa. 1989. p. 501 e 542 ,

8. Gomes da, Esboço de uma Concepção Personalista do Direito. Universidade de Lisboa. 1965. p. 226,

Recebido em: 18/9/2016

Aprovado em: 29/9/2016

Como citar este artigo:

Marques RFR. Requisição de prontuário ou ficha clínica no Brasil (Justiça, Ministério Público e Polícia) X Sigilo Médico. Revista Cadernos Ibero-Americanos de Direito Sanitário. 2016 dez., 5 supl. 1:129-142 